\title{
Natural Vibration Analysis of Long Span Suspension Bridges \\ Jianing Hao
}

\author{
Sichuan College of Architecture Technology, Deyang, Sichuan, 618000, China \\ haojianing@yeah.net
}

Keywords: large span; suspension bridge; nature vibration; estimation formula; ANSYS

Abstract. The vertical and torsional vibration basic frequency estimation formula of suspension bridge on "Wind resistant Design Specification for Highway Bridges" is introduced. Finite element model of HUMEN suspension is established. Whole vibration models and frequency are obtained by modal analysis, and it lays the foundation for further developing the flutter analysis and spectral analysis of structure. Results of the comparisons of specification and finite element model show that the results agree well. It indicates that specification estimation formula can accurate reflect the dynamic characteristics of the structure. Early in the design, the specification formulas can be used to estimate the fundamental frequency of the suspension bridge.

\section{Introduction}

The natural vibration of the suspension bridge is a vibration that is found under constant load, and the vibration characteristics of the suspension bridge is very complicated due to the influence of cable force increment. In suspension bridge scheme selection and preliminary design stage, the approximate fundamental frequency of the structure is needed to explain the influence of the change of bridge parameters on the dynamic characteristics. In the final stage of design, it is required to accurately calculate the mode and frequency of each order, so as to calculate the flutter analysis or spectral analysis, which need more accurate numerical method [1].

In this paper, the finite element model of the structure is established by using the large finite element software ANSYS, and the vibration mode and frequency of the model are analyzed in this paper, which is based on the project of HUMEN suspension bridge. Through compared with the results of the base frequency calculation of the "Wind resistant Design Specification for Highway Bridges"[2], it shows that the results of this paper is correct.

\section{Fundamental frequency calculation formula of specification}

The estimation formula of vertical bending frequency of suspension bridge is shown in formula (1).

$$
f_{b}=\frac{1.16}{\sqrt{f_{0}}}
$$

\section{( 1 )}

In the formula, $f_{0}$ is the vector high of main cable.

Estimation formula for symmetric vertical bending of suspension bridge is shown in formula (2).

$$
f_{b}=\frac{0.1}{L} \sqrt{\frac{E_{c} A_{c}}{m}}
$$

In the formula, $\mathrm{L}$ is the span of main cable, $E_{c}$ is elastic Modulus of main cable, $A_{c}$ is area of the single main cable.

Estimation formula for anti symmetric torsional frequency of suspension bridge is shown in formula (3). 


$$
f_{b}=\frac{1}{L} \sqrt{\frac{E I_{\omega}\left(\frac{2 \pi}{L}\right)^{2}+G I_{d}+\frac{1}{2} H_{g} B_{c}^{2}}{m_{d} r^{2}+m_{c} \frac{1}{2} B_{c}^{2}}}
$$

)

In the formula, $E I_{\omega}, G I_{d}$ are the constraint torsion stiffness and free torsional stiffness of the main girder. The closed box girder can be neglected restrained torsional stiffness. In the formula, $r$ as the inertia radius of the stiffening girder section, $B_{c}$ is the center distance of main cable.

Estimating the fundamental frequency of suspension bridge is shown in formula (4).

$$
f_{b}=\frac{1}{2 L} \sqrt{\frac{G I_{d}+0.05256 E_{c} A_{c}\left(B_{c}^{2} / 2\right)^{2}}{m_{d} r^{2}+m_{c} \frac{1}{2} B_{c}^{2}}}
$$

Each symbol in the formula is the same as above.

\section{Fundamental frequency calculation formula of specification}

Finite element model. HUMEN bridge preliminary design scheme is make by Highway planning and Design Institute of Transportation Ministry in 1992. The structure type is a single span double hinged suspension bridge, the span of main cable is $312 \mathrm{~m}+888 \mathrm{~m}+353.484 \mathrm{~m}$, the vector high of main cable is $84.571 \mathrm{~m}$, the area of the single main cable is $0.27 \mathrm{~m} 2$. Sling spacing is $12 \mathrm{~m}$, sling area is $0.01 \mathrm{~m} 2$. The stiffening girder is a flat steel box girder, the beam width is $33.4 \mathrm{~m}$, the beam height is $3.012 \mathrm{~m}$. Two gate tower structure of the same size, height of $147.552 \mathrm{~m}$. Each tower has three beams. Other detailed parameters are seen in the literature [1].

This paper equivalent fish bone model for suspension bridge is established by using the finite element software ANSYS. According to the different characteristics of each member's force, choose a different element. The main cable and the sling are used to bear the pulling force of the LINK10 unit. The stiffening girder, rigid arm, tower and the tower beam using BEAM4 unit. Mass and inertia moment of the stiffening girder is simulated by MASS21 element. Main cable ends is consolidated at the ground, and it is consolidated at the bottom of the tower. Rotational degrees, the lateral translational degrees and freedom along the beam length direction of stiffening girder and vertical tower beam coupling are coupled. The finite element model is shown in Figure 1.

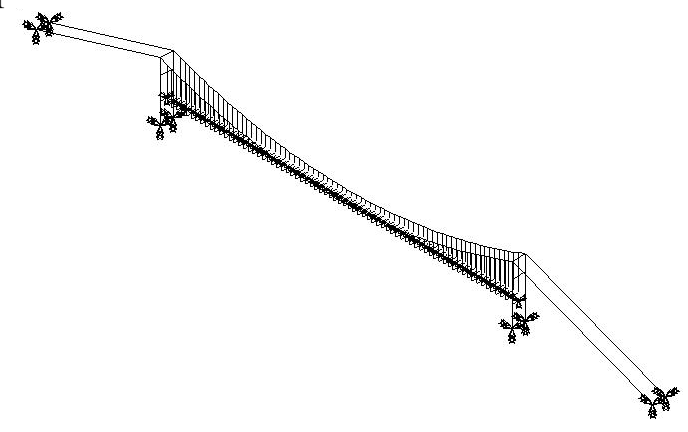

Fig. 1 finite element model of Humen Bridge

Finite element method. The dynamic characteristics of suspension bridge should be calculated as follows. 1) The initial strain of the main cable is set up, and the prestress is applied through the static calculation. 2) A finite element model is established to carry out the static analysis under the action of dead loads. 3) To preserve the shape of the static, the analysis of the natural vibration of the prestressing force.

Modal analysis. A variety of methods commonly used methods of modal analysis with iterative method, the inverse iteration method, the Rayleigh Ritz method, the subspace iteration method and Lanczos method, Rayleigh quotient iteration, determinant search method [3-4]. In this paper, the 
natural vibration analysis of a suspension bridge is carried out using the subspace iteration method of ANSYS, and the vibration mode and frequency of lateral vibration, vertical vibration and torsional vibration of the bridge are obtained, which is shown in figure $2 \sim 4$.

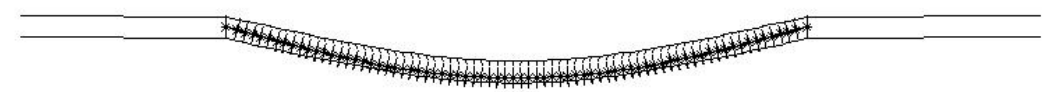

A. First order symmetric side bend $(0.0926 \mathrm{~Hz})$

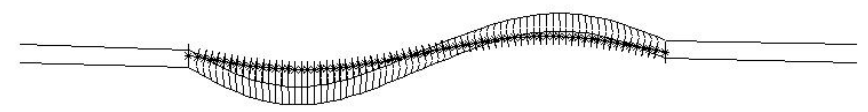

B. First order against the side bend $(0.3000 \mathrm{~Hz})$

Figure 2. Transverse vibration mode and frequency

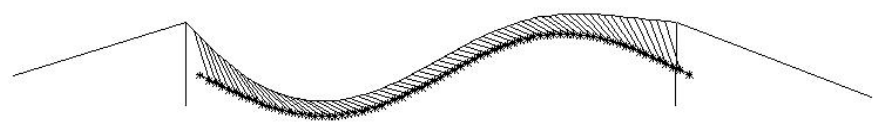

A. First order antisymmetric vertical bending $(0.1303 \mathrm{~Hz})$

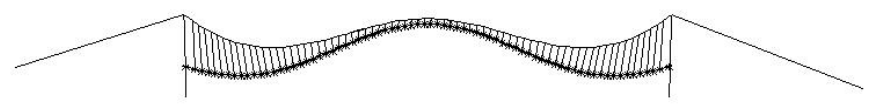

B. First order symmetric vertical bending $(0.1686 \mathrm{~Hz})$

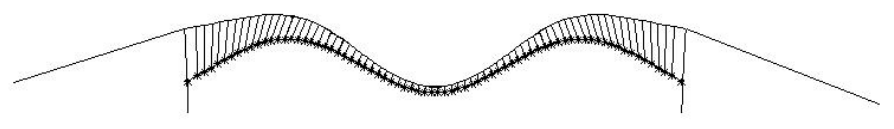

C. Two order symmetric vertical bending $(0.2260 \mathrm{~Hz})$

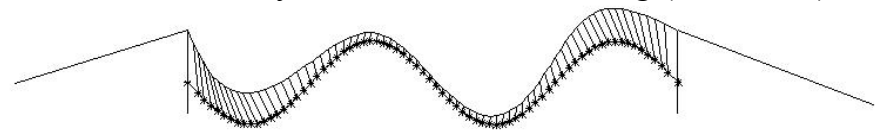

D. Two order antisymmetric vertical bending $(0.2795 \mathrm{~Hz})$

Fig. 3 Vertical vibration mode and frequency

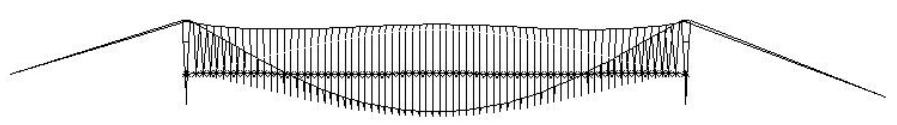

A. First order symmetric torsion $(0.3649 \mathrm{~Hz})$

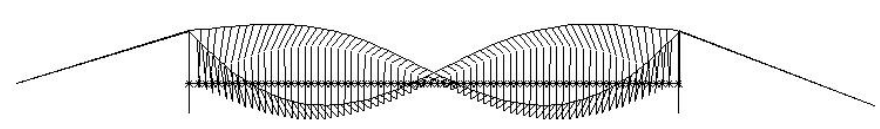

B. First order antisymmetric torsion $(0.4689 \mathrm{~Hz})$

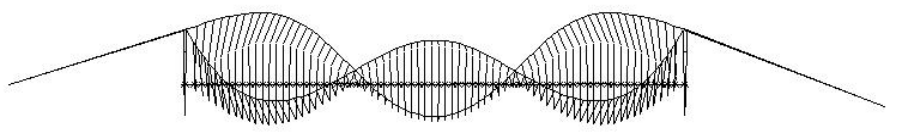

C. Two order symmetric torsion $(0.7122 \mathrm{~Hz})$

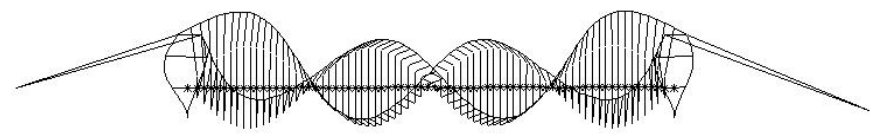

D. Two order antisymmetric torsion $(0.9519 \mathrm{~Hz})$

Figure 4 Torsional vibration mode and frequency

It can be seen from figure $2 \sim 4$ that, 1) The transverse vibration mode is the first appearance, the second is the vertical vibration mode, the torsional vibration mode finally appears, which shows that the structure has a large torsional rigidity, and the structure is not easy to torsional flutter instability. 2) Transverse mode, vertical vibration mode and torsional vibration mode are all sinusoidal curves, and 
the transverse vibration and torsional vibration are 1.5 wave, while the vertical basic mode is 2.5 wave.

\section{Fundamental frequency calculation results contrast}

The calculation results of the formula (1) formula (4) and the results of the finite element model are listed in Table 1. As can be seen from the table 1, the calculation results of specification are very close to the finite element results, the error is within 5\%. The correctness of the finite element model is proved, and it also shows that the formula can reflect the fundamental frequency of the structure accurately.

Table 1 Comparison of calculation results of fundamental frequency

\begin{tabular}{cccc}
\hline Vibration type & specification formula & Finite element & Error \\
\hline Antisymmetric vertical bending & 0.1262 & 0.1303 & $3.25 \%$ \\
Symmetrical vertical bending & 0.1678 & 0.1686 & $4.77 \%$ \\
Symmetrical torsion & 0.3608 & 0.3649 & $1.14 \%$ \\
Antisymmetric reverse & 0.4788 & 0.4689 & $2.06 \%$ \\
\hline
\end{tabular}

\section{Conclusion}

The finite element model of Humen suspension bridge is established by the large finite element software ANSYS. The vibration mode and frequency of the structure are obtained by modal analysis. The results show that the torsional vibration mode finally appears, which shows that the structure has a large torsional rigidity, and the structure is not easy to torsional flutter instability. The basic frequency of the suspension bridge is calculated by the specification formula, and the results compared with the finite element results, it shows that the calculation results are very close. The error is within 5\%, and the specification calculation formula can reflect the dynamic characteristics of the structure more accurately, and it can be used to calculate the fundamental frequency of the suspension bridge at the beginning of the design. In the design of the final stage, the frequency and vibration type can be calculated by the numerical analysis of the suspension bridge, for the further analysis and the analysis of the flutter analysis.

\section{References}

[1] Renfu Chen. The theory of large span suspension bridge [M]. Chengdu, Southwest Jiao Tong University press, 1994

[2] In the Design Institute of highway bridges, the wind resistant design code for highway bridges [S]. Beijing, People's communication press.2004

[3] Wei Huang. The simple analysis of the simple dynamic characteristics of large span steel truss arch bridge [J]. Shanxi traffic science and technology, 2010 (1), P68-70

[4] Hongwei Cai. Static and dynamic characteristics of steel truss bridge [J]. Shanxi transportation technology, 2012 (2), P27-29 